\title{
The DCU laser ion source
}

\author{
P. Yeates, ${ }^{1}$ J. T. Costello, ${ }^{1,2}$ and E. T. Kennedy ${ }^{1,2}$ \\ ${ }^{1}$ National Centre for Plasma Science and Technology (NCPST), Dublin, Ireland \\ ${ }^{2}$ School of Physical Sciences, Dublin City University (DCU), Glasnevin, Ireland
}

(Received 28 July 2009; accepted 8 March 2010; published online 27 April 2010)

\begin{abstract}
Laser ion sources are used to generate and deliver highly charged ions of various masses and energies. We present details on the design and basic parameters of the DCU laser ion source (LIS). The theoretical aspects of a high voltage (HV) linear LIS are presented and the main issues surrounding laser-plasma formation, ion extraction and modeling of beam transport in relation to the operation of a LIS are detailed. A range of laser power densities $\left(I \sim 10^{8}-10^{11} \mathrm{~W} \mathrm{~cm}^{-2}\right)$ and fluences $\left(F=0.1-3.9 \mathrm{~kJ} \mathrm{~cm}^{-2}\right)$ from a Q-switched ruby laser (full-width half-maximum pulse duration $\sim 35 \mathrm{~ns}, \lambda=694 \mathrm{~nm}$ ) were used to generate a copper plasma. In "basic operating mode," laser generated plasma ions are electrostatically accelerated using a dc HV bias (5-18 kV). A traditional einzel electrostatic lens system is utilized to transport and collimate the extracted ion beam for detection via a Faraday cup. Peak currents of up to $I \sim 600 \mu \mathrm{A}$ for $\mathrm{Cu}^{+}$to $\mathrm{Cu}^{3+}$ ions were recorded. The maximum collected charge reached $94 \mathrm{pC}\left(\mathrm{Cu}^{2+}\right)$. Hydrodynamic simulations and ion probe diagnostics were used to study the plasma plume within the extraction gap. The system measured performance and electrodynamic simulations indicated that the use of a short field-free $(L=48 \mathrm{~mm})$ region results in rapid expansion of the injected ion beam in the drift tube. This severely limits the efficiency of the electrostatic lens system and consequently the sources performance. Simulations of ion beam dynamics in a "continuous einzel array" were performed and experimentally verified to counter the strong space-charge force present in the ion beam which results from plasma extraction close to the target surface. Ion beam acceleration and injection thus occur at "high pressure." In "enhanced operating mode," peak currents of $3.26 \mathrm{~mA}\left(\mathrm{Cu}^{2+}\right)$ were recorded. The collected currents of more highly charged ions $\left(\mathrm{Cu}^{4+}-\mathrm{Cu}^{6+}\right)$ increased considerably in this mode of operation. () 2010 American Institute of Physics. [doi:10.1063/1.3374123]
\end{abstract}

\section{INTRODUCTION}

The history and development of laser ion sources (LIS) over the past 25 years are intimately linked to the development of the Q-switched laser, its continuous increase in pulse energy and decreasing pulse duration. The earliest proposal that laser plasmas could act as efficient sources of highly charged ions ${ }^{1,2}$ and as injectors for particle accelerators was discussed in the seventies. The 1980s and early 1990s saw the first large scale attempt to use LIS ions for injection studies with a $10 \mathrm{GeV}$ synchrotron. ${ }^{3}$ Initial experiments focused on low mass elements but were later extended to heavier elements. ${ }^{4}$ Further progress resulted in LIS systems being used with Van De Graaf accelerators at various facilities. ${ }^{4,5}$ More modern systems have been built upon the previous success and the growth in interest in heavy ion accelerators. $^{6-9}$ In parallel with new developments in Q-switched lasers, LIS systems utilizing $\mathrm{CO}_{2}$, excimer $\mathrm{XeCl}$, femtosecond Ti:sapphire, and picosecond Nd:yttriumaluminum-garnet lasers have all been reported. ${ }^{10}$

In this paper we shall present a thorough overview of the main components and design aspects of the DCU laser ion source. A detailed discussion of the most important aspects of laser generated plasmas in relation to the performance of a LIS will be presented. These include plasma generation, plume expansion dynamics and beam extraction using high voltage (HV) fields and ion beam transport issues. A detailed description of the system components, technologies and the detectors utilized to diagnose the extracted ion beam are presented. Initially utilizing a traditional einzel lens system the behavior of the peak ion stage and current of the DCU-LIS to varying extraction bias, $V_{\text {ext }}$ and laser fluence, $F$ is presented. The shot-to-shot stability of the extracted beam, its response to increasing source potential and the values of the collected charge for each charge state are measured. The portion of the ion beam, contained within the extraction gap, is studied via an ion probe, and simulated using a hydrodynamic code. Such studies form the input variables for electrodynamic simulations of the effectiveness of the traditional beam transport system and expose its limitations. To counter this, a unique "continuous einzel array" electrostatic lens system is simulated and implemented, resulting in enhanced beam transport. Substantial increases in the collected charge and maximum charge state are demonstrated.

\section{LASER ION SOURCES: GENERAL OVERVIEW}

Extraction of charged species from laser ablation of targets occurs over an extended range of irradiances for virtually every element in the periodic table. For such irradiances above $\sim 10^{9} \mathrm{~W} \mathrm{~cm}^{-2}$, the common mechanism of plasma generation generally starts with evaporation from the target surface, with plasma electrons being heated by laser energy to hundreds of $\mathrm{eV}$. The generation of highly charged ions is 
driven by electron-ion collisions, indeed the transfer of laser energy via inverse bremsstrahlung, leads to an $\left(I \lambda^{2}\right)^{2 / 3}$ dependence for $T_{e}$, where $I$ and $\lambda$ are laser intensity and wavelength. ${ }^{11}$ The general trends reported in the literature have demonstrated plasma generation with increasing intensity, and from higher mass elements. In recent years, for high irradiance studies $\left(I \sim 10^{15} \mathrm{~W} \mathrm{~cm}^{-2}\right)$, charge states of up to $50+$, with kinetic energies ranging from 9-50 MeV (Refs. 12 and 13) for a range of elements ( $\mathrm{Al}, \mathrm{Au}, \mathrm{Bi}, \mathrm{Pt}, \mathrm{Ta}$, and $\mathrm{W})$ have been observed.

One category of ion source using laser ablation employs $\mathrm{HV}$ dc or pulsed extraction of the plasma plume, with concomitant charge state separation along the flight path. Overwhelmingly these systems extract plasma ions along the main axis of plasma expansion. As a consequence linear HV systems yield high current densities and high peak currents for a considerable range of charge states. The use of extraction fields and the resulting electrostatic acceleration of plasma species also improves the emittance $\varepsilon=\pi r r^{\prime}$ (emittance is the area of the ellipse in phase space with axes of length $2 r$ and $2 r^{\prime}$ which contains roughly $50 \%$ of the beam intensity). Effectively, the smaller the emittance, the greater the proportion of the beam that can reach the detector. Conversely space-charge effects, lead to beam divergence and subsequent loss of ions.

The use of extraction fields creates a number of experimental challenges and usually requires numerous tradeoffs and secondary technologies, e.g., electrostatic focusing, ramping voltages, etc. to achieve the desired performance. However despite these issues, it has been demonstrated that such systems ${ }^{13,14}$ are superior to other ion sources, e.g., electron cyclotron resonance as they can deliver current densities of multicharged ions, at least two orders of magnitude higher. It is into this class or category that our system falls. In Sec. III, we discuss in detail the principles of operation and considerations, which arise when HV fields are used to extract, focus, and separate charged, high velocity plasma ions.

\section{LASER ION SOURCES: GENERAL PRINCIPLES}

For a LIS, the dynamics of laser-target interactions and subsequent plasma formation and expansion are as important as ion electrodynamics and beam transport; in essence the plasma generation and ion transport are concurrently important in laser ion sources. However this also provides the opportunity to optimize the source by having an extended range of both laser and ion transport parameters to control.

\section{A. Plasma generation and expansion}

First, the delivery of a focused laser pulse onto a target is not $100 \%$ efficient. A percentage of the laser light will be reflected (depending upon the reflectivity of the material and laser wavelength). The remainder of the pulse penetrates to a distance $\delta$, defined as the skin depth and which can be calculated using the expression $\sqrt{2 / \omega \mu \sigma}$. Here $\omega$ is the angular frequency of the laser radiation, $\mu$ is the magnetic permeability and $\sigma$ is the target conductivity. Usually $\delta$ is a fraction of the laser wavelength. During the first phase of laser irradia- tion, electrons in the target conduction band transfer the absorbed optical energy to the target lattice, resulting in melting. This in turn reduces the reflectivity, which enhances absorption of the laser. Continued laser irradation thus leads to vaporization. At this point further energetic collisions and radiation absorption drive ionization, liberating more free electrons, which in turn (via ion-electron collisions) rapidly increase the average charge state. For intensities below $10^{14} \mathrm{~W} \mathrm{~cm}^{-2}$ the dominant mechanism for energy transfer from the laser field to the plasma is inverse bremsstrahlung (IB) ${ }^{15}$ The efficiency of this process has been known to decrease with increasing intensity $I$ and decreasing laser wavelength. ${ }^{16}$ Conversely longer pulse durations increase the efficiency of IB absorption. Thus it is not always desirable to use excessive laser intensity. Indeed one must carefully choose the laser parameters (especially wavelength), depending upon the yield and distribution of charge states desired. LIS studies, using power densities, $P \geq 10^{10}-10^{13} \mathrm{~W} \mathrm{~cm}^{-2}$, pulse durations, $\tau_{L} \leq 100 \mathrm{~ns}$, and laser wavelength $\lambda \approx 1000 \mathrm{~nm}$, have demonstrated that absorption of incident laser radiation can be up to $\approx 70 \%-90 \%$ efficient. ${ }^{15}$ In the early phase of free hydrodynamic expansion, three-body, radiative, and dielectronic recombination processes occur, reducing the average charge state. The electron density $N_{e}$ remains high and the Debye length $\lambda_{d}$ remains small $\left(\propto \sqrt{T_{e} / N_{e}}\right)$. The biggest factor in limiting the yield of highly charged ions after some expansion distance $L$, is three body recombination, ${ }^{16}$

$$
R_{3 B} \cong 10^{-26} Z_{\mathrm{ion}}^{3} \frac{N_{e}}{T_{e}^{9 / 2}}\left[\mathrm{~cm}^{3} \mathrm{~s}^{-1}\right] .
$$

Thus to maximize the highly charged ion yield $R_{3 B}$ must be minimized and so, a high temperature low-density plasma is desirable. The duration of the plasma pulse is considerably longer than the laser pulse. The length of the drift space between the target and an extraction anode determines this duration and is usually called the field-free region. Depending upon the system geometry, it can vary from a few centimeters to over $1 \mathrm{~m}$. At the anode, the full-width halfmaximum (FWHM) of the ion pulse can be estimated as ${ }^{16}$

$$
\tau_{1 / 2}=\frac{2 L \Delta v}{\left(v^{2}-\Delta v^{2}\right)}
$$

Here, $\Delta v$ is the characteristic half-width of the ion velocity spectrum $f(v)$. The ratio $v / 2 \Delta v$ remains approximately constant, at $1.6 \pm 0.5$ for the power densities of interest here. Experimental scaling laws ${ }^{16}$ have been established for plasmas similar to those reported here

$$
\begin{aligned}
& v(\mathrm{~cm} / \mathrm{s})=87 P^{0.42}\left[\mathrm{~W} / \mathrm{cm}^{2}\right], \\
& \tau_{I 1 / 2}(\mu \mathrm{s})=2 \times 10^{6} P^{-0.43} L\left[\mathrm{Wm} / \mathrm{cm}^{2}\right] .
\end{aligned}
$$

The number of ions $N$ and the current $I$ extracted through a given aperture (preferably circular) decrease steeply with increasing $L$, i.e., $N \propto 1 / L^{2}$ and $I \propto 1 / L^{3}$. Therefore the choice of $L$, effectively adjusts the duration of the ion signal. However the necessity to use HV extraction places pronounced limits on the minimum value of $L$ for a particular value of $P$. Reducing $L$ increases the maximum current density $J$ that 
can be extracted, by virtue of minimizing the recombination rate $R_{3 B}$. However, since $N_{e}$ increases dramatically as $L \rightarrow 0$, one approaches the limit of HV breakdown which is proportional to $d^{1 / 2}$ (the length over which the voltage is applied) for $d$ greater than $1 \mathrm{~cm} .{ }^{17,18}$ Second the Debye length $\lambda_{d}$, is directly related to the degree of shielding of the plasma particles. Even if the extraction field can be maintained, its penetration into the plasma can be drastically reduced. This significantly compromises the efficiency of a LIS.

\section{B. Extraction dynamics}

Once the plume begins to enter the extraction gap (of width $d$ ) a complex and relatively poorly understood process occurs. The theory concerning the leakage of plasma particles crossing what is defined as the "triple point" (the boundary between the plume edge, the extraction grids, and the vacuum region or gap) is normally applied to stationary plasmas such as rf generated plasmas. However for a rapidly moving surface, where the curvature and surface particle density are both high and fluctuating rapidly, such as a laser plasma plume, some design generalizations can be made. First the electric field should impart substantially more kinetic energy to the ions than their thermal kinetic energy. This is to ensure that the flight time in the drift tube is predominantly due to electric field acceleration (which is charge dependent). Second, due to the high $N_{e}$ in the gap, Debye shielding of the plume will usually limit efficiency of extraction, and ions will acquire a final kinetic energy lower than $\sim Z_{i} e V_{\text {ext }}$ ( $Z_{i}$ is the ion charge and $V_{\text {ext }}$ the extraction voltage. Finally, the (spatial) density profile of the laser plasma will be convex in shape which will result in a distortion of the extraction field. This field distortion will in turn cause the high current ion beam to diverge strongly upon injection into the drift tube. This situation is exacerbated by the thermal kinetic energy of the ions whose velocity vectors are not parallel to the drift tube (an unavoidable aspect of laser plasmas), and also by inherent space-charge repulsion within each individual ion bunch.

There are various techniques for dealing with such effects; however all involve compromises to the LIS performance. First, the "field-free-region," $L$ can be increased until $N_{e}$ drops sufficiently to permit greater E-field penetration of the plume. This will not only reduce the field distortion within the extraction gap but should also allow for higher source potentials to be utilized. Higher potentials enhance charge bunch separation during flight time, reducing the flight time and thus minimizing beam expansion. However as stated earlier, $I \propto 1 / L^{3}$, and $J \propto A / L^{3}$ (where $A$ is the extraction aperture area). This in turn places a severe limit on the maximum possible extracted current density. This limitation can be minimized using a higher source potential since, $J \sim V_{\text {ext }}^{3 / 2} / d^{2}$ (Child-Langmuir relation) with subsequent advantages already stated above. However doing so dramatically limits the yield and maximum charge state of ions which can be extracted, due to recombination during adiabatic expansion. For LIS systems, some attempts to compensate for the flux variation in the ion emission surface have been made. These lead to strong modulation of the extracted beam current using a multiaperture anode ${ }^{19}$ or concave ex-

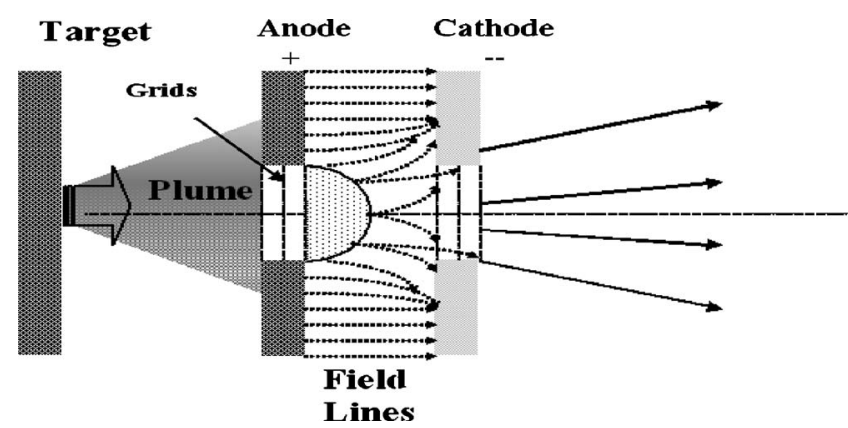

FIG. 1. Generation/expansion region and extraction gap. Electric field lines become distorted by the convex profile of the plasma front in the gap. This leads to premature defocusing and inefficient electrostatic coupling of the electric field to the plasma ions. The distance $L$, between the target and anode is called the field-free region.

traction electrodes. ${ }^{20-23}$ One can also minimize the diameter of the extraction aperture relative to the plume radius so that only paraxial plasma ions are extracted, reducing beam divergence after injection. Of course, this also lowers the extracted current density.

The traditional approach to single aperture systems is the "Pierce gun geometry." 24 The beam is created in an idealized one-dimensional (1D) diode and accelerated to the required kinetic energy. The space-charge-limited current density for ions with charge-state $Z_{i}$ and mass $m_{i}$ in a gap of width $d$ and applied voltage $V_{\text {ext }}$ is given by the expression ${ }^{25}$

$$
J_{C}=\frac{4 \varepsilon_{0}}{9} \sqrt{\frac{2 Z_{i} e}{m_{i}}} \frac{V_{\mathrm{ext}}^{3 / 2}}{d^{2}}
$$

where $J_{C}$ is the vacuum current density in a $1 \mathrm{D}$ geometry and $\varepsilon_{0}$ is the permittivity of free space. One must be careful not to exceed $J_{C}$ for a selected $V_{\text {ext }}$ and $d$. If the actual ion flux $J_{P}$ exceeds $J_{C}$, then the plasma front expands into the extraction gap, reducing the effective value of $d$, until flux balance is restored. In this case, the source surface (plume front) moves to the right in Fig. 1, into the extraction gap, producing a convex profile in the plume density.

Conversely, if $J_{P}<J_{C}$, the surface becomes concave and is directed away from the extraction gap. While the above applies mainly to dc plasma sources, the considerations remain the same for streaming dynamic plumes. Strong distortion of the already convex laser-plasma plume front leads to significant beam defocusing and subsequent beam loss at some critical extraction voltage. Finally, it is of critical importance that a fine mesh covers both the extraction aperture and the entrance aperture of the drift tube. The first mesh at the extraction aperture ensures that the field-free region is indeed field-free. The second mesh prevents the extraction field from entering the drift tube, where the field lines guide the extracted ions into the drift tube wall.

\section{Ion beam transport}

Upon injection into the drift tube of length $D$, the plume gradually breaks up into regions of spatially separated charge and eventually into discrete bunches of ions each of a well defined charge state. The total flight time of an ion is the sum of the drift time in the field-free region $T_{L}$, the time spent 
under electrostatic acceleration in the extraction gap $T_{d}$ and the flight time in the drift tube, $T_{D}$. Thus the total flight time is $^{26}$

$$
T\left(U_{0}, L\right)=T_{L}+T_{d}+T_{D} .
$$

In addition the total kinetic energy of an ion, $U$ with initial kinetic energy $U_{0}$ is given by

$$
U=U_{0}+Z_{i} e d E_{d}
$$

(the electric field in the accelerating region is given by $E_{d}$, $\left.=V_{\text {ext }} / d\right)$. Equation (6) can then be rewritten ${ }^{26}$

$$
T\left(U_{0}, L\right)=L \frac{\sqrt{2 m_{i}}}{2 \sqrt{U_{0}}}+\frac{d \sqrt{2 m_{i}}}{\sqrt{U_{0}}+\sqrt{U_{0}+Z_{i} e V}}+\frac{D \sqrt{2 m_{i}}}{2 \sqrt{U_{0}+Z_{i} e V}} .
$$

With increasing $N_{e}$, the final kinetic energy of the accelerated ions will depart from the calculated value. Indeed some groups ${ }^{27}$ have observed extraction efficiencies of less than $30 \%$ for high fluence aluminum plasma ions. Finally, the energy spread of ions, related to some initial ion temperature $T_{i}$, within the laser plasma plume generally tends to complicate identification of charge states. Unless a high $V_{\text {ext }}$ and large $D$ are present, ions will not separate sufficiently in the drift tube to be easily distinguished at the detector. However a large value of $D$ will certainly lead to loss of signal through particle collisions with ambient gas molecules, space-charge driven beam expansion, and recombination within the ion beam. All of the above loss mechanisms increase dramatically with the average charge state $\bar{Z}$, and/or the thermal kinetic energy of the plume (both drive radial beam expansion) and/or as the flight time increases. Conversely, such effects can be minimized by (i) higher source potential (decreased flight time $T_{D}$ ), (ii) deliberately increasing the extracted beam diameter (lowers the space-charge repulsive force), or (iii) application of electrostatic optics to guide and control beam dynamics. Such ion optics, e.g., einzel lenses, can be used to confine a beam transversely against spacecharge mutual repulsion and thermal expansion. However the focusing strength of such electrostatic lenses diminishes with increasing beam energy, so care must be taken in their design and application.

In designing the DCU laser ion source, we minimized the field-free region $L$. This has resulted in a "compact, highpressure" laser ion source, whose peak current and average charge state $\bar{Z}$, are high compared with other LIS of similar configuration or size.

\section{EXPERIMENTAL SETUP}

A 1.2 J Q-switched Ruby laser (FWHM pulse duration $\sim 35 \mathrm{~ns}, \lambda=694 \mathrm{~nm}$ ) is focused onto a copper target, via a $21 \mathrm{~cm}$ focal length planoconvex lens. The target surface is inclined at $25^{\circ}$ to the system optical axis. The focal spot, of approximate diameter $120 \mu \mathrm{m}$, produces power densities $P$ of $2 \times 10^{9}-2.4 \times 10^{11} \mathrm{~W} \mathrm{~cm}^{-2}$ and fluences of $0.1-8.5 \mathrm{~kJ} \mathrm{~cm}^{-2}$ by variation of the laser pulse energy. The target is mounted inside a nylon "mold" or prechamber (Fig. 1). The internal cavity allows for two parallel copper plates to be mounted. The first is used to secure the target, and the

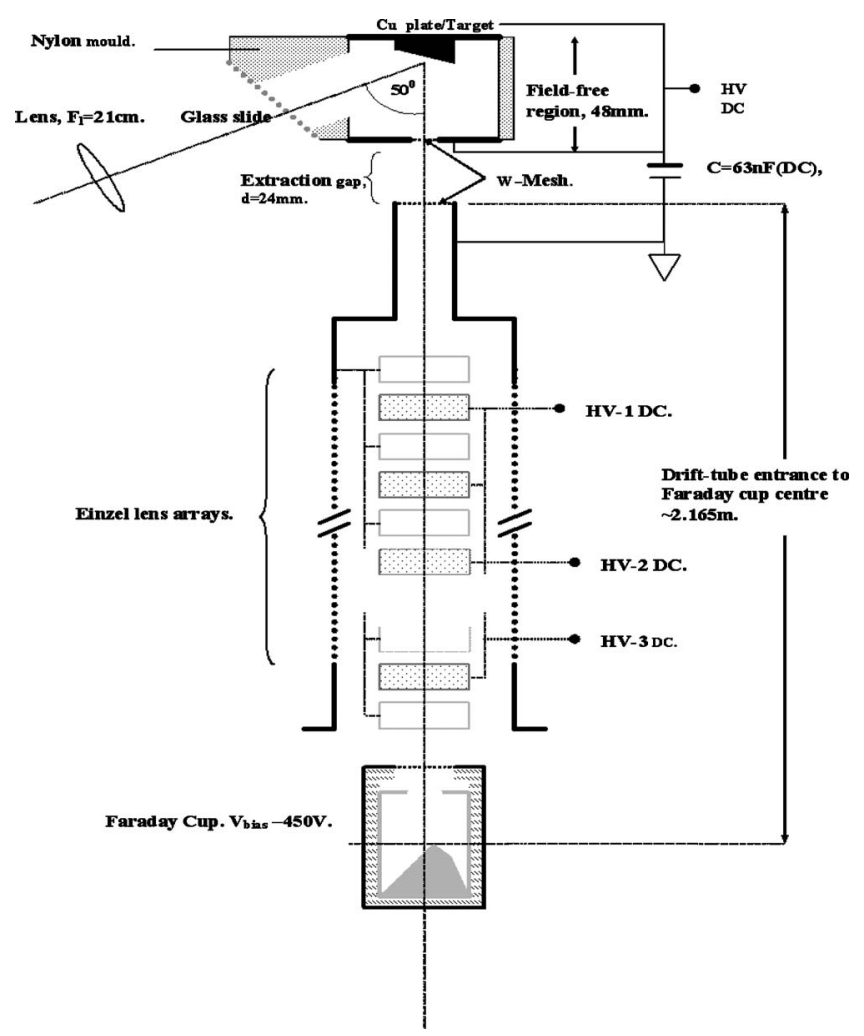

FIG. 2. Experimental setup. The total distance from the target surface to the geometric center of the Faraday cup is $2.24 \mathrm{~m}$. HV extraction is achieved using a dc bias $(\leq 20 \mathrm{kV})$. High density tungsten mesh covers both the extraction aperture at the anode and also the entrance aperture to the drift tube (cathode). The drift tube is terminated with an irregular geometry Faraday cup. Pressure in the target chamber averaged $\sim 2 \times 10^{-6}$ mbar and was $\sim 0.9 \times 10^{-7}$ mbar in the drift tube and $\sim 3.5 \times 10^{-6}$ mbar in the diagnostic chamber during the measurements.

second constitutes the exit aperture for ion extraction across the gap of width $d$. An entry port, covered by a glass slide is used to permit laser beam access to the target. The prechamber is required to prevent arcing from the plume to the main vacuum chamber. Using such a nylon mold minimizes the amount of surface area which is at a HV bias (in place of a metal prechamber). Both front and back plates are connected to the bias HV supply and the field between them is approximately zero, thus defining our "field-free region" of length $48 \mathrm{~mm}$ and diameter $45 \mathrm{~mm}$. The exit aperture or anode is circular and of diameter $6 \mathrm{~mm}$. It is in turned covered by five layers of tungsten fine mesh. Each individual layer has a transmission of $81 \%$ transparent, giving a net transparency of $\sim 35 \%$. Referring to Fig. 2, the extraction gap $d$ is $24 \mathrm{~mm}$ wide and leads to the entrance aperture of the drift tube, forming the cathode. The cathode aperture is also covered, by four layers of tungsten mesh. This density of mesh serves two purposes. First it limits the total particle transmission. We wish to maximize the highest charge state generated, and also the yield of such ions which concomitantly requires the optimization of the power density, $P$ on the target. However large particle fluxes across the extraction gap put a ceiling on the peak extraction voltage $V_{\text {ext }}$. Therefore we use the mesh to limit the particle flux, while simultaneously permitting a high value of $P$. Second, the greater the mesh density, the smaller the electric field leakage. This is true for leakage into 
the drift tube from the cathode, but also within the field-free region between the target surface and the anode aperture. The bias across the extraction gap is maintained by a $63 \mathrm{nF}$, $40 \mathrm{kV}$ capacitor bank operated in dc mode. A simple wire ion probe was placed in front of the cathode mesh to measure the particle flux entering the drift tube when HV fields are not present. The drift tube, of length $D \sim 2.16 \mathrm{~m}$ is $80 \mathrm{~mm}$ in diameter and contains a number of einzel electrostatic lens elements, each biased separately (discussed later). This allows for beam collimation and final stage focusing. A Faraday cup, biased to $-450 \mathrm{~V}$ is located at the end of the drift tube.

The Faraday cup, a cylinder of diameter $5 \mathrm{~cm}$, and length $6 \mathrm{~cm}$, has an entrance aperture of diameter $3 \mathrm{~cm}$. The cup contains an off-center nonsymmetrical cone, tapered at the tip. The entire cup is placed within a Teflon sleeve for electrostatic isolation. Both cup and sleeve are then mounted inside an aluminum cylinder, whose entrance aperture is also covered with tungsten mesh. Various studies of Faraday cup designs have concluded that irregular or nonplanar geometries for the cups internal volume demonstrate superior secondary electron capture. ${ }^{28-32}$ The ideal cup should not present any surface perpendicular to the incoming ion beam. Second the depth to diameter ratio of a cup should be at least $1: 1$, while the entrance aperture should be less than the cups outer diameter, to minimize secondary electron emission. High-density mesh is required for the outermost aperture, to dampen any electronic noise. Finally a second, isolated mesh or ring, known as a "secondary electron suppressor" should be placed immediately in front of the cups entrance aperture and biased to a high negative voltage. Initially a single layer of $\mathrm{W}$ mesh, biased to $-5 \mathrm{kV}$ was placed $4 \mathrm{~mm}$ from the front aperture of the Faraday cup in order to compensate for secondary electron emission. However for $V_{\text {ext }}$ values up to 10 $\mathrm{kV}$, we observed no discernable differences in the time of flight (TOF) signal beyond the standard shot-to-shot variation. We concluded that our Faraday cup geometry successfully recaptured the majority of secondary electrons. Thus the secondary electron suppressor mesh was removed. dc extraction did not exceed $\sim 20 \mathrm{kV}$ due to difficulties with the ambient atmosphere in the laboratory which made arcing an issue.

\section{BASIC OPERATIONAL PERFORMANCE}

In characterizing the system performance, the laser fluence and the extraction voltage are the most important variables to be investigated. Fluences varying from $F=0.09$ to $8.5 \mathrm{~kJ} \mathrm{~cm}^{-2}$ at an extraction voltage of $V_{\mathrm{ext}}=5 \mathrm{kV}$ were used to determine the system dependence on this parameter. Figure 3 displays the TOF dependency on $F$. At the lowest fluence $\left(85 \mathrm{~J} \mathrm{~cm}^{-2}\right)$, the TOF profile contains only two ion species, $\mathrm{Cu}^{+}$and $\mathrm{Cu}^{2+}$ and initial currents are extremely low $I<50 \mu \mathrm{A}$. This is likely to be more strongly determined by the efficiency of the extraction and beam transport than the absence of more highly charged ions albeit in small numbers present during the plasma formation phase. At the peak fluence of $8.5 \mathrm{~kJ} \mathrm{~cm}^{-2}$, the recorded TOF signal saturates and the maximum collected current does not exceed

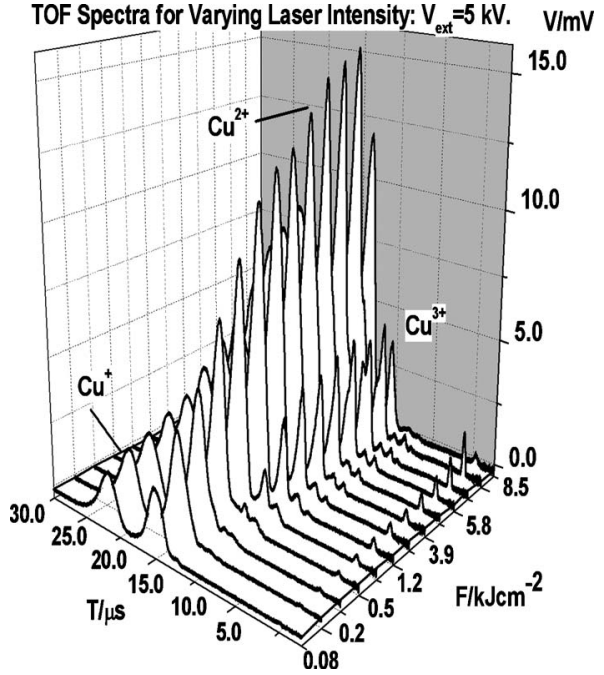

FIG. 3. TOF Faraday cup signal at $V_{\mathrm{ext}}=5 \mathrm{kV}$ for a range of laser fluences $\left(F=0.09-8.5 \mathrm{~kJ} \mathrm{~cm}^{-2}\right)$.

$I \sim 500 \mu \mathrm{A}\left(\mathrm{Cu}^{2+}\right)$. The detection of more highly charged ions does not occur until $F>1.0 \mathrm{~kJ} \mathrm{~cm}^{-2}$ and the detected signals levels from $\mathrm{Cu}^{4+}$ and $\mathrm{Cu}^{5+}$ ions are extremely low $(I<10 \mu \mathrm{A})$.

The values of $V_{\text {ext }}$ and $F$ in this instance were the minimum allowed for stable signal detection. Figure 4 displays the TOF signal response to $V_{\text {ext }}$ for a fixed fluence $\left(F=3.9 \mathrm{~kJ} \mathrm{~cm}^{-2}\right)$. This figure demonstrates a clear turning point in the collected current as $V_{\text {ext }}$ increases. The current detected at the highest extraction voltage $(15 \mathrm{kV})$ was in fact lower than that at $V_{\mathrm{ext}}=5 \mathrm{kV}$ for the highest fluence. This result was unexpected. The issue of a turning point in the recorded current is more clearly displayed in Fig. 5. Here the peak currents from $\mathrm{Cu}^{+}$to $\mathrm{Cu}^{3+}$ are plotted against the extraction bias. Each time, dependent traces in Figs. 3 and 4 are an average of ten shots to ensure good signal stability and to reduce the impact of "transient" signals such as those from ionized gas particles (i.e., H, N, and O). The inset in Fig. 6 displays the peak recorded voltage for the $\mathrm{Cu}^{2+}$ ion bunch over ten shots for $V_{\text {ext }}=5,9$ and $15 \mathrm{kV}$ allowing the shot-toshot response to be observed. The average peak voltage for

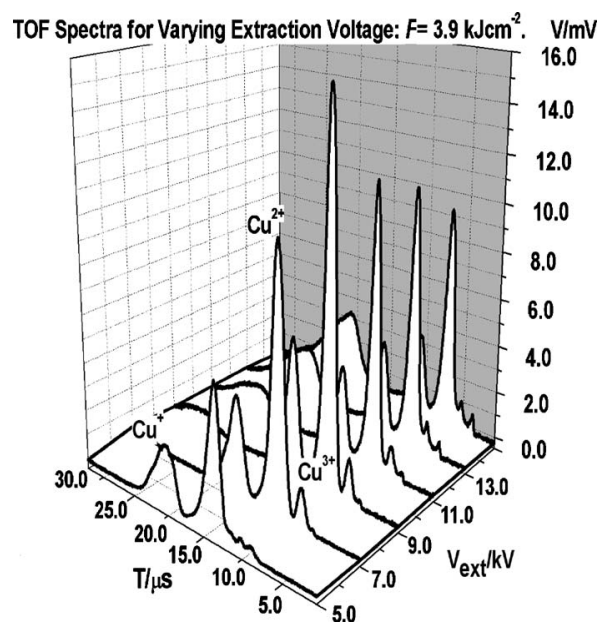

FIG. 4. TOF Faraday cup signal for $F=3.9 \mathrm{~kJ} \mathrm{~cm}^{-2}$ for a range of extraction voltages $\left(V_{\mathrm{ext}}=5-15 \mathrm{kV}\right)$. 


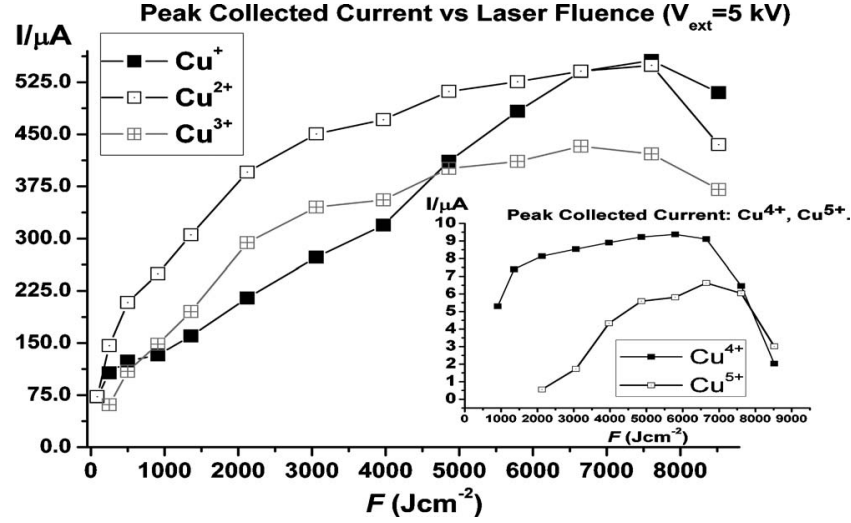

FIG. 5. Peak recorded current for $\mathrm{Cu}^{+}, \mathrm{Cu}^{2+}$ and $\mathrm{Cu}^{3+}$ at $V_{\text {ext }}=5 \mathrm{kV}$ for a range of fluences $\left(F=0.09-8.5 \mathrm{~kJ} \mathrm{~cm}^{-2}\right)$. (Inset) Peak currents for $\mathrm{Cu}^{4+}$ and $\mathrm{Cu}^{5+}$ ion bunches.

each $V_{\text {ext }}$ is also displayed, as is the "average variation" from this value. As the extraction bias is increased the average deviation from the ten shot average also increases. Increasing the extraction bias should ensure superior beam transport by reducing the flight time of the beam and thus reducing the impact of space-charge forces which tend to broaden the beam, resulting in beam loss. This in turn should result in improved shot-to-shot stability. A turning point in the extracted current from a LIS as $V_{\text {ext }}$ increases has been observed before ${ }^{16,21-23}$ and is linked to distortion of the electric field lines within the extraction gap. This results in "prefocusing" of the ion beam a short distance inside the drift tube, followed by strong space-charge driven expansion and finally beam loss. The collected charge for the observed ion bunches was lower than expected (see Table I) and did not exceed $99 \mathrm{pC}$. In the course of our experiments it was observed that the influence of the einzel lens units was strongly dependent upon the extraction bias. As $V_{\text {ext }}$ increased the first einzel lens unit became increasingly ineffective. The increasing $K_{e}$ (kinetic energy) of the injected ion bunches coupled with the short length of the lens unit means that the ions spent insufficient time in the presence of the focusing field of that einzel unit. The second einzel unit proved more effective but the long distance to the Faraday cup resulted in strong beam loss above a critical focusing voltage. The maximum bias used on this lens unit was $V_{2}<2.0 \mathrm{kV}$. The last einzel unit was most effective in increasing the recorded signal. The maximum bias used was $V_{3}=6 \mathrm{kV}$. Beyond that no further enhancement in the collected signal was recorded. Given the high fluences and extraction voltages used, and in comparison with other systems of similar length, it was determined that the system performance was not optimized. This was

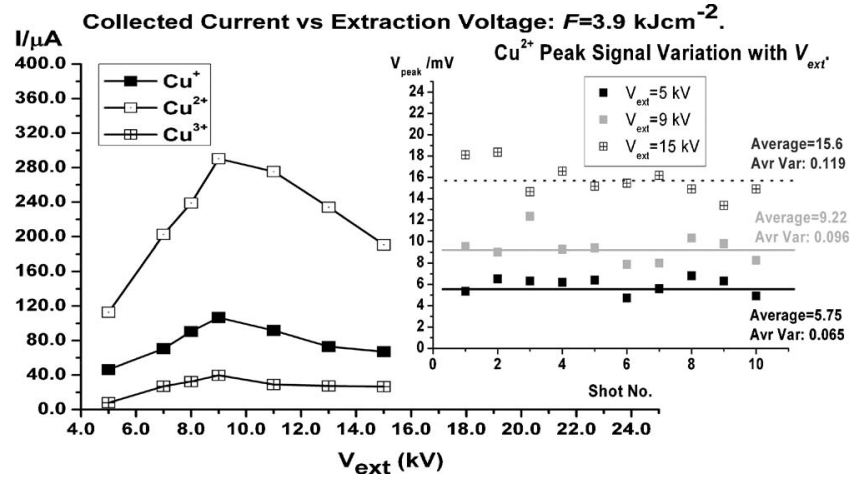

FIG. 6. Collected current for $\mathrm{Cu}^{+}, \mathrm{Cu}^{2+}$, and $\mathrm{Cu}^{3+}$ for $F=3.9 \mathrm{~kJ} \mathrm{~cm}^{-2}$ for a range of extraction voltages. (Inset) Shot to shot variation in the peak signal recoded via the Faraday cup for $\mathrm{Cu}^{2+}$ for $V_{\mathrm{ext}}=5,9$, and $15 \mathrm{kV}$.

particularly evident given the extremely short field-free region employed in our work. On average the field region in most LIS systems are usually greater than half a meter. ${ }^{16}$ The data obtained here highlighted two issues for the DCU-LIS. First, low throughput. This stems from inefficient beam collimation and transport. This issue originates in the plasma plume dynamics within the extraction gap and is exacerbated by distortion of the bias field. The latter problem originates from the plasma density and average charge state within the extraction gap. Thus both of the above challenges to optimum system performance are a direct result of our decision to attempt to minimize the length of the field-free region in this system in order to maximize the extracted current and charge state.

To address the above issues the injected plasma density and signal duration within the extraction gap were studied, and electrodynamic simulations were used to attempt to elaborate upon beam loss mechanisms in our system. This is discussed in Sec. VI.

\section{PLASMA SIMULATION AND BEAM TRANSPORT MODELING}

A primary concern for LIS systems is efficient extraction, transport and collection of ions. One of the most widely used approaches to address this issue is to model beam transport via SIMION ${ }^{\mathrm{TM}}$. The latter is a powerful and well known software package. Electrostatic elements can be modeled in three-dimensional (3D) and ion parameters such as charge, kinetic energy, launch angle, and mass can be inputted. An important aspect of modeling beam transport is the choice of the initial values. We diagnosed the laser plasma plume in two ways, first, simulating plasma generation via the

TABLE I. Maximum and minimum collected charge for $\mathrm{Cu}^{+}, \mathrm{Cu}^{2+}$, and $\mathrm{Cu}^{3+}$ charge states for the upper and lower limits of the extraction voltage, $V_{\mathrm{ext}}$ and fluence, $F$ focused on to the target.

\begin{tabular}{lccccrr}
\hline \hline Ion stage & $\begin{array}{c}V_{\text {ext }} \\
(\mathrm{kV})(\min )\end{array}$ & $\begin{array}{c}V_{\text {ext }} \\
(\mathrm{kV})(\max )\end{array}$ & $\begin{array}{c}F_{\text {min }} \\
\left(\mathrm{J} \mathrm{cm}^{-2}\right)\end{array}$ & $\begin{array}{c}F_{\text {max }} \\
\left(\mathrm{J} \mathrm{cm}^{-2}\right)\end{array}$ & $\begin{array}{c}Q_{\text {min }} \\
(\mathrm{pC})\end{array}$ & $\begin{array}{r}Q_{\text {max }} \\
(\mathrm{pC})\end{array}$ \\
\hline $\mathrm{Cu}^{+}$ & 5 & 13 & 85 & 8520 & 72.6 & 98.3 \\
$\mathrm{Cu}^{2+}$ & 5 & 13 & 85 & 8520 & 72.7 & 210.6 \\
$\mathrm{Cu}^{3+}$ & 5 & 13 & 85 & 8520 & 02.7 & 9.2 \\
\hline \hline
\end{tabular}




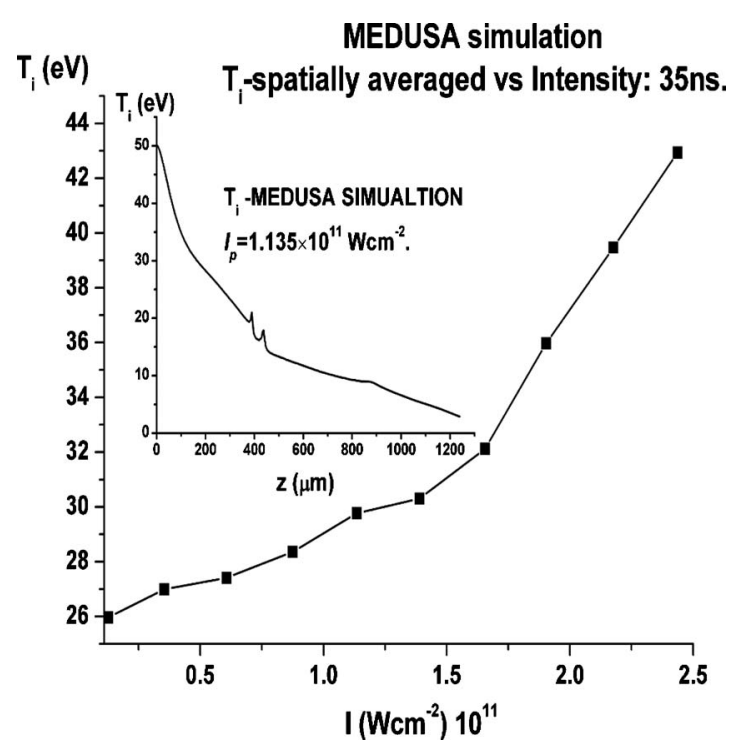

FIG. 7. Spatially averaged ion temperatures at the end of the laser pulse ( $\sim 35 \mathrm{~ns})$ vs laser intensity. (Inset) Spatial profile of the ion temperature for a intensity, $I \sim 1.13 \times 10^{11}\left(\mathrm{~W} \mathrm{~cm}^{-2}\right), F=3.97 \mathrm{~kJ} \mathrm{~cm}^{-2}$.

MEDUSA (Ref. 33) code; and second with an ion probe. We begin by presenting the results of simulations.

\section{A. MEDUSA simulations}

In order to determine the laser plasma properties we utilized the MEDUSA (Ref. 33) laser plasma code. The code was run for ten intensities over the experimental range studied for copper laser plasmas. The time step was set to $1 \mathrm{ps}$, while the number of cells was 200 (giving an initial cell size of $\sim 6 \mu \mathrm{m})$. The ion temperature at the end of the laser pulse was then spatially averaged for each input laser intensity and these values are plotted in Fig. 7. This procedure gives an approximate value for the average kinetic energy within the plume at the moment rapid adiabatic expansion begins. Also of interest is the average charge state within the plasma. The MEDUSA code returns the average charge, and despite predicting charge states up to $\mathrm{Cu}^{16+}$, recombination processes caused the average charge state of the plume entering the extraction gap to be much lower. The highest electron temperatures predicted by MEDUSA was $130 \mathrm{eV}$, while peak electron densities at the end of the laser pulse ranged from $N_{e}$ $\sim 8-10 \times 10^{20} \mathrm{~cm}^{-3}$.

\section{B. Ion probe measurements}

A simple wire ion probe was used to measure the ion current, TOF and duration of the plasma at the cathode. The tungsten tip was of length $5 \mathrm{~mm}$ and diameter $400 \mu \mathrm{m}$, and biased to $-150 \mathrm{~V}$. Plume signals were obtained for a range of laser energies. Figure 8 shows the recorded signals. The inset compares the FWHM of the ion signal with that predicted by Eq. (4) in Sec. III A. Peak currents up to the maximum intensity used, ranged from 12 to $36 \mathrm{~mA}$ depending on the laser intensity. Such measurements cannot be done in the presence of a HV extraction field. However they are useful when quantifying the plume energies and pulse durations.

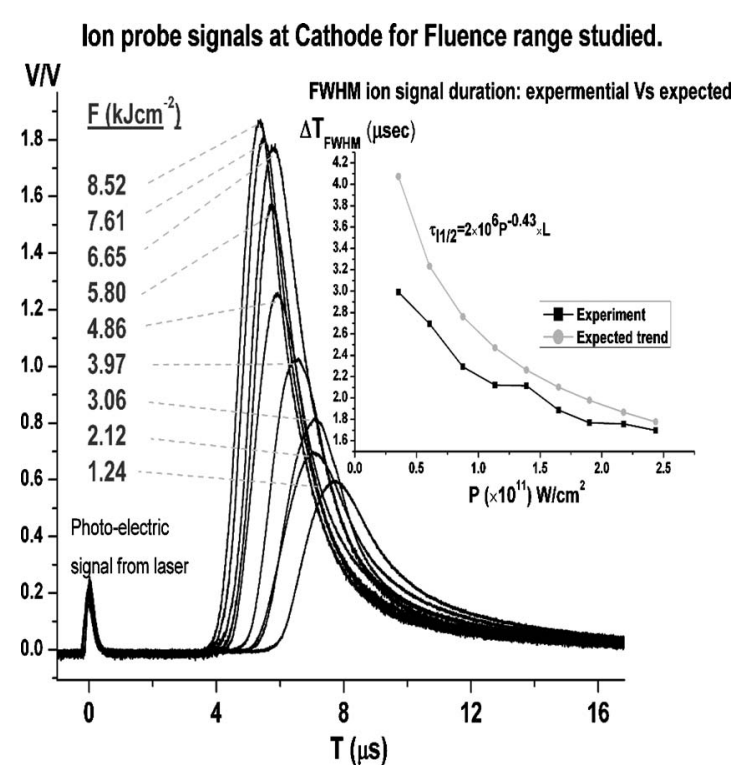

FIG. 8. TOF ion probe signals at the cathode for all fluences used. (Inset) measured vs expected pulse durations from Eq. (4).

Figure 9 shows the velocities of the plume edge and peak, obtained from TOF measurements for a range of on-target irradiances.

These values are compared with the empirical relation $V_{\mathrm{TOF}} \propto P^{N}$. The TOF currents can be fitted with the function ${ }^{34}$ in Eq. (9) below

$$
I(t) \propto \frac{A}{t^{4}} \exp \left[\frac{m_{i}}{2 k T_{K L}}\left(\frac{x}{t}-\nu_{d}\right)^{2}\right] .
$$

Here $T_{K L}$ is the Knudsen-layer temperature, $v_{d}$ is the centerof-mass velocity, $m_{i}$ is the ion mass, $A$ is a scalar, and $x$ is the length of the flight path, in this case $72 \mathrm{~mm}$ (target surface to probe tip). The velocities of particles that originate in thermal equilibrium from a hot volume should approximately exhibit a Maxwellian distribution ${ }^{35}$ given by

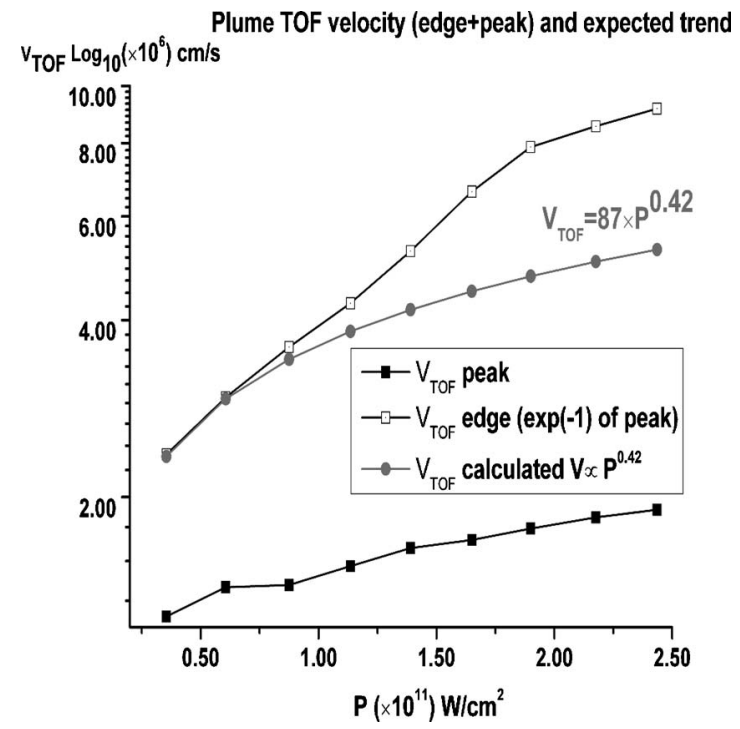

FIG. 9. TOF velocities (edge and peak) measured vs expected velocities based upon Eq. (3). 


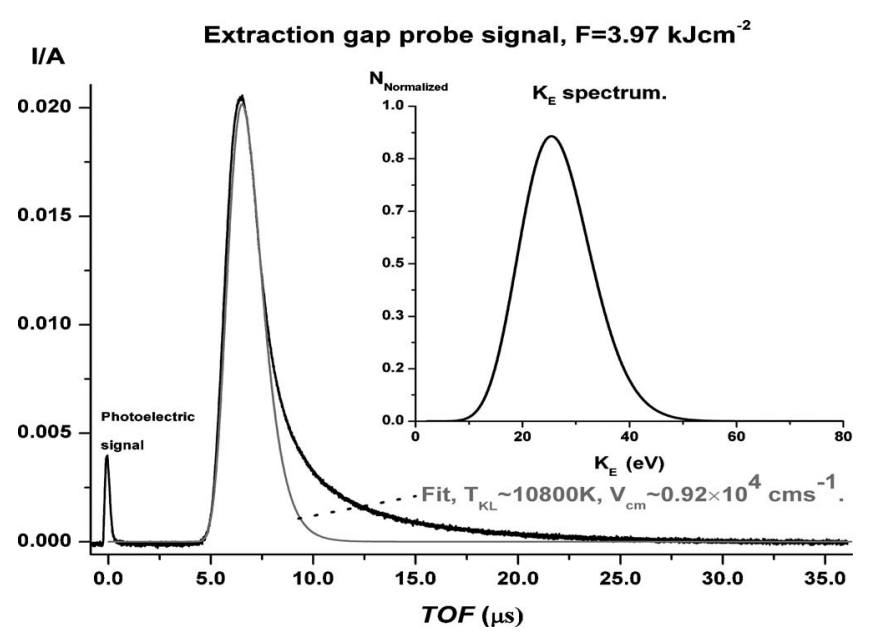

FIG. 10. TOF ion probe signals at the cathode for $I \sim 1.13$ $\times 10^{11}\left(\mathrm{~W} \mathrm{~cm}^{-2}\right)$ showing the current fit using Eq. (9). (Inset) Kinetic energy distribution derived from Eq. (10) using the temperature obtained from Eq. (9).

$$
f(v) \sim v^{3} \exp \left(-m v^{2} / 2 k T\right) .
$$

Thus by fitting Eq. (9) to our TOF probe signals we can deduce the temperature and center of mass velocity of the plume. This information in turn can be used to create a velocity distribution via Eq. (10). When this function is plotted against kinetic energy (in eV) the peak of the distribution can then be compared with the MEDUSA temperatures at the end of the laser pulse. Figure 10 shows the fitted curve to a TOF probe signal. The inset displays $f(v)$ versus $K_{E}$ (the kinetic energy). This process was repeated for all intensities studied, and the results are summarized in Table II. It is possible that turbulence created when the plume traverses the dense mesh at the anode shifts the energy spectrum of the ions to lower energies. Indeed such an interaction would be inherently lossy and would lead to an increase in the number of low energy ions (as observed). However the peak $K_{E}$ would be unaffected. The MEDUSA ion temperatures are also presented for comparison over the fluence range studied. The edge velocities returned by MEDUSA are on the order of 3.5-3.7 $\times 10^{6} \mathrm{~cm} \mathrm{~s}^{-1}$. However by the time the plume reaches the probe, peak velocities have dropped to $\sim 1.2-1.9$ $\times 10^{6} \mathrm{~cm} \mathrm{~s}^{-1}$. Combining probe measurements with simulation values helps ensure that input parameters to SIMION are reliable. Indeed the temperatures returned by MEDUSA are in good agreement with those energies deduced via our probe signals. The high currents recorded in the extraction gap by the ion probe in comparison to the collected TOF signals (in Sec. V) further highlight the issue of efficient beam extraction and transport along the drift tube.

\section{SIMION simulations}

We first attempted to reproduce the beam transport performance of the three independent einzel lens "units." A lens unit was composed of three parallel metal rings/cylinders. The center ring was biased at a given voltage while the outer two were grounded. Each lens ring was made of stainless steel, of diameter $60 \mathrm{~mm}$, and length $30 \mathrm{~mm}$ for the central ring, while the outer two grounded rings were $25 \mathrm{~mm}$ long.
TABLE II. Laser intensity, fluence, fitted plasma temperature $\left(T_{K L}\right)$, peak kinetic energy (probe data), and simulated temperatures from MEDUSA.

\begin{tabular}{ccccc}
\hline \hline$I\left(\mathrm{~W} \mathrm{~cm}^{-2}\right) \times 10^{11}$ & $\begin{array}{c}F \\
\left(\mathrm{~kJ} \mathrm{~cm}^{-2}\right)\end{array}$ & $\begin{array}{c}T_{K L} \\
(\mathrm{~K}) \text { fit }\end{array}$ & $\begin{array}{c}K_{\text {E-Peak }} \\
(\mathrm{eV}) \text { fit }\end{array}$ & $\begin{array}{c}\text { MEDUSA } T_{i} \\
(\mathrm{eV})\end{array}$ \\
\hline 0.35 & 1.24 & 8500 & 21.4 & 26.0 \\
0.61 & 2.12 & 10100 & 24.2 & 28.1 \\
0.87 & 3.10 & 10450 & 25.8 & 32.1 \\
1.13 & 3.97 & 10800 & 27.3 & 34.3 \\
1.39 & 4.86 & 11175 & 29.1 & 36.9 \\
1.65 & 5.79 & 11500 & 30.5 & 39.7 \\
1.90 & 6.64 & 12500 & 33.2 & 41.4 \\
2.18 & 7.61 & 14550 & 36.9 & 42.0 \\
2.44 & 8.52 & 16600 & 38.3 & 42.9 \\
\hline \hline
\end{tabular}

Three lens units were placed at the front, middle and end of the drift tube. Simulations assumed no initial beam divergence. Under such an assumption, simulated beam collimation and transport using the three lens units was adequate as displayed in Fig. 11. However any attempt to simulate a diverging ion beam, for any extraction bias or initial kinetic energy indicated that efficient and complete beam transport was extremely challenging. If the plume possessed a high divergence angle, or if interion charge repulsion exceeded a critical value, then it would undergo strong space-charge and thermally driven expansion. This issue was especially pronounced if the simulated beam was composed of successively charged ion bunches. The high divergence angle of the injected beam and the beam kinetic energy at high values of $V_{\text {ext }}$ meant that satisfactory performance using traditional, discrete einzel lens unit would not suffice for use with a LIS.

A new and innovative approach was needed and so, after some preliminary simulations, it was than decided to attempt to construct a continuous einzel array (see Fig. 12). Initial simulations indicated that an extended array would offer better capture and collimation of ions, especially at high $V_{\text {ext }}$ values. The design was motivated by a number of multi element systems, albeit for other applications. ${ }^{36-40}$ The final electrostatic optics configuration implemented consists of three long einzel lens arrays, biased independently. One unit, $0.8 \mathrm{~m}$ long was composed of 18 individual rings and placed at one end of the drift tube. A second unit $0.5 \mathrm{~m}$ long comprised 13 individual rings and was placed near the other end of the drift tube. The final unit was $0.25 \mathrm{~m}$ long and composed of five individual rings, placed immediately in front of the Faraday cup for focusing. Figure 13 shows a 3D SIMION plot of the total system. Initial parameters in SIMION were chosen to reproduce as closely as possible experimental conditions within the limits of the capabilities of SIMION. 100 ions for each ion group $\left(\mathrm{Cu}^{+}\right.$to $\left.\mathrm{Cu}^{4+}\right)$ were created or "born" at the surface of the copper target. These ions were aligned parallel to the target surface over a diameter of $120 \mu \mathrm{m}$ (laser spot diameter). Ions so created were mono-energetic $(27.3 \mathrm{eV})$, the initial kinetic energy $K_{E}$ was taken from column 4 of Table II and these values were derived from ion probe measurements within the gap. They represent a best average initial energy $\left(U_{0}\right)$ for ion electrodynamic simulations in SIMION. Laser generated plasma plumes expand in a conelike manner ${ }^{41-45}$ typically at an angle of $\sim 30^{\circ}-35^{\circ}$. 


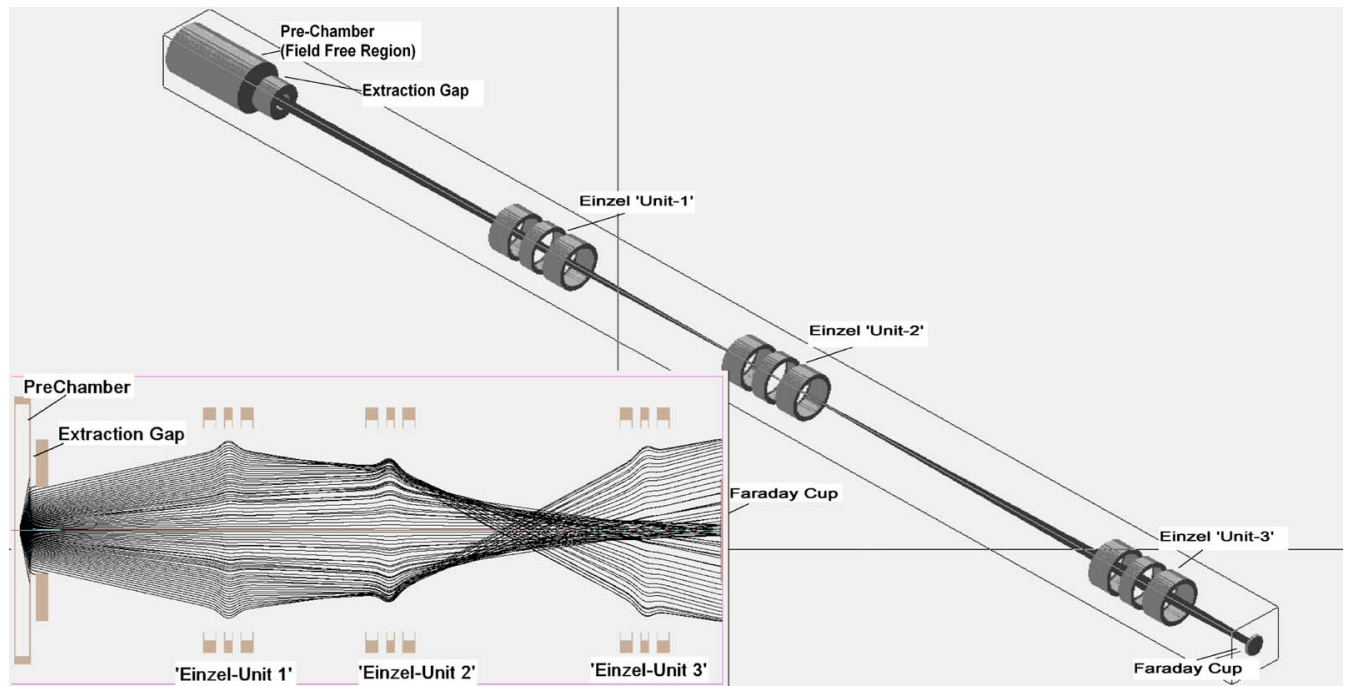

FIG. 11. (Color online) ISO-3D schematic of the first beam transport system in SIMION. (Inset) 2D cross section, showing the ion flight path for $\mathrm{Cu}^{+}$ $\left(K_{E} \sim 25 \mathrm{eV}\right)$ and $V_{\mathrm{ext}}=5 \mathrm{kV}$. Bias values: lens unit- $1=0.4 \mathrm{kV}$, lens unit- $2=1.8 \mathrm{kV}$, and lens unit- $3=5.6 \mathrm{kV}$.

This occurs via adiabatic expansion upon termination of the laser pulse. However this lateral expansion is not continuous. During adiabatic expansion the plasma plume diameter becomes relatively constant and the plasma plume then expands rapidly away from the target surface at a constant velocity.

To reproduce this aspect of laser plasma plumes we chose a space-charge Coulombic value for inter ion repulsion $\left(\sim 5 \times 10^{13} \mathrm{C}\right)$ which produced a $30^{\circ}-35^{\circ}$ expansion cone and this allowed the beam expansion rate to change as the beam expanded resulting in a reduction in interion forces.

There is insufficient data within the literature on quantifying the space-charge forces within an ion beam extracted from a laser generated plume. Thus we decided not to use the "launch angle" function in SIMION for launching ions at various angles. Such an approach would conserve the launch angle. No numerical results were derived from these simulations. They do however allow us to investigate possible causes for the rather poor system throughput using the traditional einzel three lens system presented in Sec. V. A large range of variables were tested, including divergence of the ion beam, initial kinetic energy (from MEDUSA simulations),

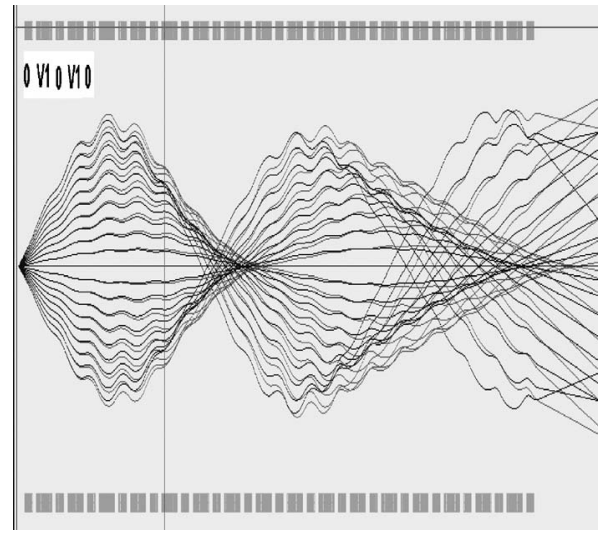

FIG. 12. Simulation of a continuous einzel array. Total number of elements 33. Charge state $\mathrm{Cu}^{+}, \mathrm{Cu}^{2+}$. Launch energy $\sim 5 \mathrm{keV}\left(\mathrm{Cu}^{+}\right), 10 \mathrm{keV}\left(\mathrm{Cu}^{2+}\right)$. Grounded elements are labeled "0," charged elements are labeled "V1." charge state and extraction voltage along with various combinations of einzel array bias. While too numerous to present here in their entirety, a number of overall trends deduced from the simulations were confirmed in subsequent experiments. First, as previously mentioned a high $V_{\text {ext }}$ required a large einzel lens bias to achieve sufficient focusing. In contrast to the single lens units, the voltage required for the einzel arrays were more moderate. Second, we found experimentally, that for low extraction voltages and high laser energy it was important to collimate the plume as early as possible, resulting in continuous increases in the bias voltage on einzel array-1. We interpret this to be the result of rapid thermally driven beam expansion upon injection into the drift tube, which must be compensated by high values of $V_{\text {ext }}$. Indeed as $V_{\text {ext }}$ was increased, the influence of array- 1 on the collected signal was diminished and as a result, both array- 2 and array- 3 required increased bias to ensure efficient collection of ions. Simulations indicated that for high values of both $V_{\text {ext }}$ and array bias, the injected beam could undergo multiple focus/defocus cycles of the beam (Fig. 12).

Initial tests indicated that with proper selection of einzel array bias values for fluences of $3.97 \mathrm{~kJ} \mathrm{~cm}^{-2}$ and $V_{\text {ext }}$

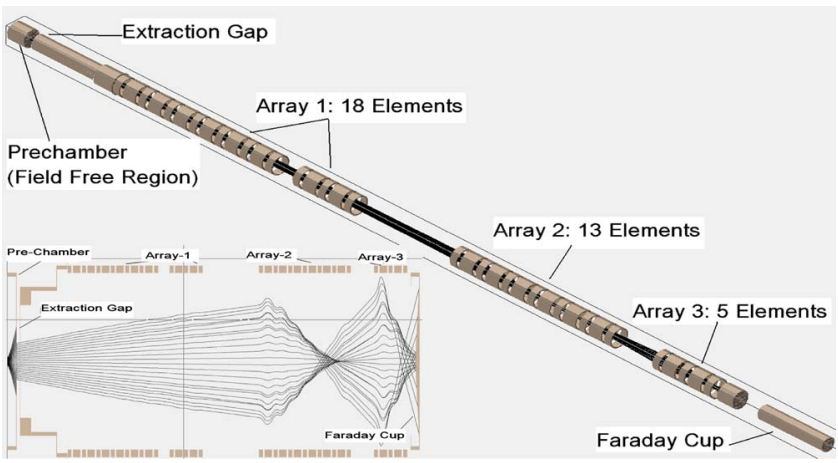

FIG. 13. (Color online) ISO-3D schematic of the second beam transport system in SIMION. (Inset) 2D cross section, showing the ion flight path, for $\mathrm{Cu}^{+}\left(K_{E} \sim 25 \mathrm{eV}\right)$, and $V_{\mathrm{ext}}=5 \mathrm{kV}$, bias values: array- $1=0.9 \mathrm{kV}$, array- 2 $=2.2 \mathrm{kV}$, and array $-3=3.4 \mathrm{kV}$. 


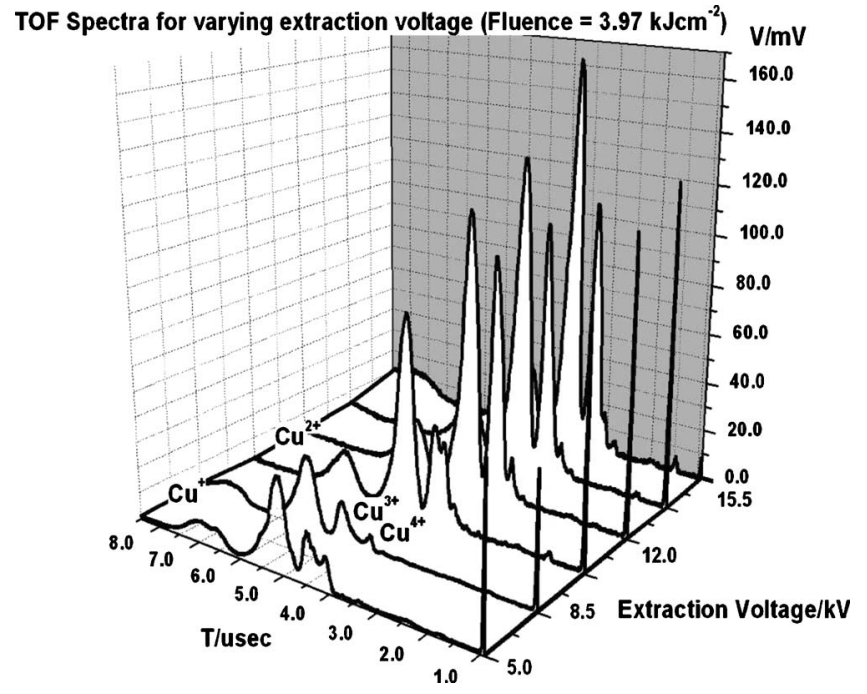

FIG. 14. TOF Faraday cup signal at $F=3.97 \mathrm{~kJ} \mathrm{~cm}^{-2}$ for various extraction voltages.

$\sim 5 \mathrm{kV}$ the peak recorded current for $\mathrm{Cu}^{2+}$ increased by a factor of 2.5 and at high extraction bias, by a factors of $\sim 8-10$. In contrast, complete beam loss occurred if einzel array-1 was biased too high for a particular value of $V_{\text {ext }}$. SIMION also indicated moderate changes in the position of the various foci for differently charged ions $\left(\mathrm{Cu}^{+}-\mathrm{Cu}^{4+}\right)$. This implied that einzel array bias values could result in favorable capture of a particular charge state, at the expense of other charge states. These studies were purely relative and were used to investigate possible inefficiencies in the traditional three-element einzel lens system initially tested in comparison with a more advanced beam transport system. Figures 11 and 13 give a good overview of the system layout using the two beam transport configurations implemented here.

In Sec. VII, the optimum performance of the experimental system utilizing the continuous einzel array will be presented. The array bias values were varied to maximize the amplitude of the collected TOF signals for a range of fluences and extraction voltages. This procedure permitted the system to be operated in "enhanced mode."

\section{ENHANCED OPERATIONAL PERFORMANCE}

Figures 14 and 15 show the TOF signal recorded by the Faraday cup for both extraction voltage and laser fluence delivered to the target in enhanced mode. As seen in Fig. 14, peak ion current signals recorded grow rapidly with $V_{\text {ext }}$, while the highest charge state observed depended strongly on the laser fluence. For all extraction voltages, separation of $\mathrm{Cu}^{+}$from $\mathrm{Cu}^{2+}$ in the TOF traces remained strong. However above $V_{\text {ext }} \sim 7 \mathrm{kV}$, the resolution was not as good and the $\mathrm{Cu}^{3+}$ and $\mathrm{Cu}^{4+}$ peaks were somewhat overlapped necessitating deconvolution to resolve them. For each ion stage the time dependent signal was approximately Gaussian. This function was used to integrate the time dependent current for each ion, and thus determine the total extracted/collected charge. For $\mathrm{Cu}^{+}-\mathrm{Cu}^{5+}$ the individual charge packet is displayed in Figs. 16(a)-16(d). For those cases where a current trace strongly deviated from a Gaussian profile, a numerical

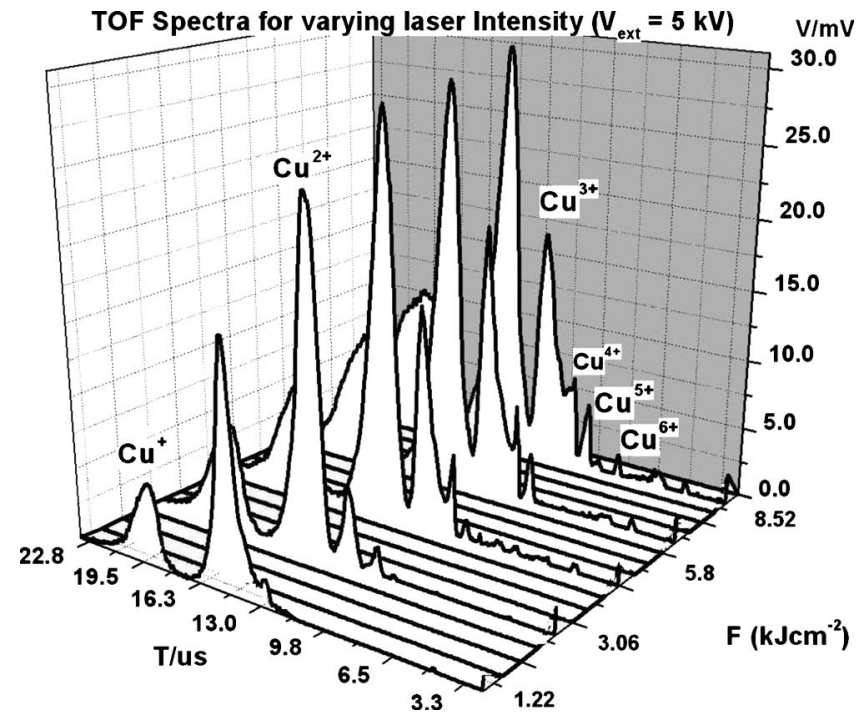

FIG. 15. TOF Faraday cup signal at $5 \mathrm{kV}$ extraction voltage for various laser fluences.

integration was performed. For each extraction voltage used, there was a pronounced limit on the allowed laser energy. Exceeding this limit led to arcing across the extraction gap. This limit can be clearly seen in Fig. 16(b), where as $V_{\text {ext }}$ increased, the maximum laser fluence which could be sustained before arcing occurred decreased from 8.5 to $4 \mathrm{~kJ} \mathrm{~cm}^{-2}$.

For each value of $V_{\text {ext }}$ and $F$, the einzel lens array bias values were varied to maximize the recorded peak signal. In all cases the $\mathrm{Cu}^{2+}$ signal was the largest and thus Fig. 16(b) shows a clear and smooth trend over all values of $V_{\text {ext }}$ and $F$. Saturation is evident at very high extraction voltages in at least some cases, especially Fig. 16(c). While it is possible that this is due to errors in the deconvolution procedure, the $\mathrm{Cu}^{5+}$ current trace did not require any deconvolution, yet it also demonstrated the same trend, that of increasing charge yield up to $13 \mathrm{kV}$, followed by a saturation in the charge yield from 13 to $7 \mathrm{kV}$. This is related to the issue of overfocusing in the drift tube at high bias values. If the plasma density within the extraction gap is sufficiently high, then Debye shielding of the plume distorts the electric field lines within the gap. This not only prevents efficient coupling of field lines to ions within the plume center, but also accelerates ions along trajectories nonparallel to the system axis. This results in increasing beam loss as $V_{\text {ext }}$ increases.

In fact we observed that einzel array voltages which maximized the $\mathrm{Cu}^{2+}$ signal reduce the peak current of the more highly charged ions. This was most apparent when $V_{\text {ext }}$ was increased. However a simple increase in the bias voltages on the einzel arrays to restore collimation/collection, the strength of which scales linearly with charge state. Our SIMION simulations indicate that for a particular value of $V_{\text {ext }}$ and einzel array bias, the ion path lengths, point of focus, number of foci, TOF and rate of divergence following focus, scales strongly with ion charge. Table III displays the charge resolved peak currents, $I_{\text {n-peak }}$, recorded for the maximum allowed fluence for each extraction voltage. The collected charge for all observed ions increases slowly and in a non- 

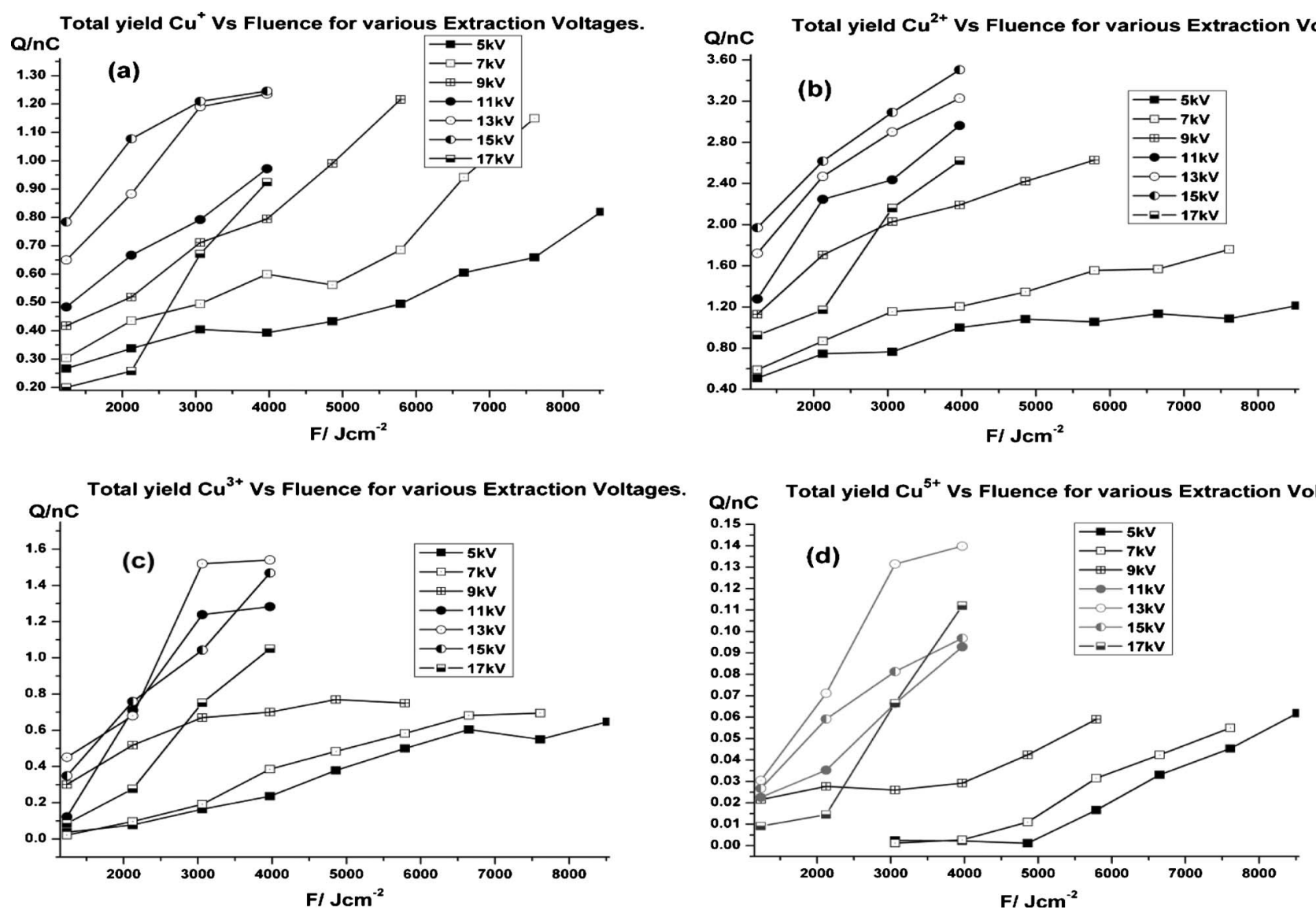

FIG. 16. [(a)-(d)] Collected charge for $\mathrm{Cu}^{+}-\mathrm{Cu}^{3+}$ and $\mathrm{Cu}^{5+}$, vs laser fluence for all extraction voltages.

linear fashion with increasing fluence at low values of $V_{\text {ext }}$. However, for a given laser fluence the collected charge increases strongly with $V_{\text {ext }}$. It was possible to increase $V_{\text {ext }}$ beyond $16 \mathrm{kV}$, where we observed a gradually decreasing peak signal for all ions, which collapsed beyond $18 \mathrm{kV}$ due to breakdown. At $V_{\text {ext }}=16-16.5 \mathrm{kV}$, and for $d=24 \mathrm{~mm}$, the extraction current, exceeds the Child-Langmuir limit [Eq. (5)] for $\mathrm{Cu}^{+}$to $\mathrm{Cu}^{4+}$ ions which would certainly lead to strong defocusing of the injected beam immediately after the cathode and a concomitant drop in collection efficiency, irrespective of the fluence or einzel bias values. Of course such an issue could be rectified by decreasing the extraction gap width $d$, but at high source potential this leads to arcing across the extraction gap.

The convex nature of the plasma plume front is clearly demonstrated in Table IV. Here the expected peak current density $\left(J_{C}\right)$ and the peak current $\left(I_{C}\right)$, calculated from the Child-Langmuir relation [Eq. (5)] is presented for $\mathrm{Cu}^{+}$to $\mathrm{Cu}^{6+}$ at an extraction voltage of $15 \mathrm{kV}$. Peak currents from this relation were obtained using the anode aperture area ( $\sim 28 \mathrm{~mm}^{2}$ ) to convert theoretical current densities $J_{C}$ $\left(\mu \mathrm{A} \mathrm{mm}^{-2}\right)$ to theoretical currents $I_{C}$ (milliampere).

These are compared with the experimental collected peak current $I_{\exp }$ (milliampere) in column 4 of Table IV for $V_{\text {ext }}=15 \mathrm{kV}$. Column 5 of Table IV indicates the gain between the theoretical and experimental values $\left(I_{C} / I_{\exp }\right)$. As outlined in Sec. III B, if the actual current $\left(I_{\text {exp }}\right)$ exceeds the Child-Langmuir limited current $\left(I_{c}\right)$ then the plasma front becomes convex. The resulting distortion of the extraction

TABLE III. Peak currents recorded by the Faraday cup.

\begin{tabular}{cccccccr}
\hline \hline \multirow{2}{*}{$\begin{array}{c}V_{\text {ext }} \\
(\mathrm{kV})\end{array}$} & $\begin{array}{c}F_{\text {MAX }} \\
\left(\mathrm{kJ} \mathrm{cm}^{-2}\right)\end{array}$ & $\mathrm{Cu}^{+}$ & $\mathrm{Cu}^{2+}$ & $\mathrm{Cu}^{3+}$ & $\mathrm{Cu}^{4+}$ & $\mathrm{Cu}^{5+}$ & $\mathrm{Cu}^{6+}$ \\
\hline 5 & 8.52 & 0.22 & 0.60 & 0.31 & 0.13 & 0.10 & 0.016 \\
7 & 7.61 & 0.32 & 1.02 & 0.62 & 0.33 & 0.20 & 0.025 \\
9 & 5.79 & 0.44 & 1.66 & 1.44 & 0.55 & 0.22 & 0.054 \\
11 & 3.97 & 0.54 & 2.26 & 1.95 & 0.62 & 0.26 & 0.058 \\
13 & 3.97 & 0.66 & 2.76 & 1.97 & 0.90 & 0.27 & 0.053 \\
15 & 3.97 & 0.77 & 3.26 & 2.16 & 1.27 & 0.34 & 0.098 \\
17 & 3.97 & 0.61 & 2.56 & 1.65 & 0.91 & 0.21 & 0.054 \\
\hline \hline
\end{tabular}


TABLE IV. Child-Langmuir current density relation vs recorded maximum currents $\left(\mathrm{Cu}^{+}\right.$to $\left.\mathrm{Cu}^{6+}\right)$ for $V_{\text {ext }}$ $=15 \mathrm{kV}$.

\begin{tabular}{lccccc}
\hline \hline Ion & $\begin{array}{c}J_{C} \\
\left(\mu \mathrm{A} \mathrm{mm}{ }^{-2}\right)\end{array}$ & $\begin{array}{c}I_{C} \\
(\mathrm{~mA})\end{array}$ & $\begin{array}{c}I_{\exp } \\
(\mathrm{mA})\end{array}$ & $\begin{array}{c}\text { Increase factor } \\
\left(I_{C} / I_{\text {exp }}\right)\end{array}$ & Convex plasma front \\
\hline $\mathrm{Cu}^{+}$ & 21.25 & 0.60 & 0.77 & 1.28 & Yes \\
$\mathrm{Cu}^{2+}$ & 30.05 & 0.85 & 3.26 & 3.83 & Yes \\
$\mathrm{Cu}^{3+}$ & 36.80 & 1.04 & 2.16 & 2.07 & Yes \\
$\mathrm{Cu}^{4+}$ & 42.50 & 1.12 & 1.27 & 1.13 & Yes \\
$\mathrm{Cu}^{5+}$ & 47.51 & 1.34 & 0.34 & $\ldots$ & No \\
$\mathrm{Cu}^{6+}$ & 52.05 & 1.47 & 0.98 & $\ldots$ & \\
\hline \hline
\end{tabular}

field lines causes strong ion beam divergence and ultimately loss of beam. As indicated in Table IV collected currents for $\mathrm{Cu}^{5+}$ and $\mathrm{Cu}^{6+}$ are below the expected theoretical values. We associate this with a number of loss mechanisms. These include ion collisions with the ambient atmosphere, spacecharge forces and three body recombination processes which have a third power dependency on the ion charge. Such loss mechanisms would be more pronounced for highly charged ions. The $I_{\exp }$ values are likely to be much higher just behind the cathode at the beginning of the drift tube and so we expect experimental current densities to be even higher than experimental current density at that point. The convex nature of the plasma front within the extraction gap results directly from the high plasma plume density which enters the gap and this originates from the use of a short field-free region in our system.

\section{DISCUSSION}

It is clear from our data that two mechanisms dominate the performance of our system. The first consideration is plasma plume-anode mesh interaction. The second is beam transport, between cathode and detector. It is clear from Figs. 14 and 15 that total throughput and peak current from our system are more sensitive to $V_{\text {ext }}$ than to $F$. This is to be expected given the form of the Child-Langmuir law, i.e., $J \propto V_{\text {ext }}^{3 / 2}$. The peak reported current for $\mathrm{Cu}^{2+}$ for a dc extraction voltage of $V_{\text {ext }} \sim 15 \mathrm{kV}\left(F=3.97 \mathrm{~kJ} \mathrm{~cm}^{-2}\right)$ was 3.26 $\mathrm{mA}$. Direct comparisons with other systems are complicated by the large variation in both design and experimental parameters reported. For example, some systems ${ }^{22,46,47}$ utilize very short drift tubes $(\sim 10 \mathrm{~cm})$ and current measurements are not charge resolved. Others employ "energy focusing" via two stage ramping ${ }^{48}$ or dc bias extraction. ${ }^{49}$ This strongly affects the peak current detected at some instant irrespective of whether it is charge resolved or not. In many cases, no extraction bias is utilized ${ }^{50-56}$ and electric sectors or energy analyzers are required to charge separate ions of different charge after some initial drift tube length. One issue however common to all systems is the $V_{\text {ext }}^{3 / 2}$ dependence alluded to above. Referring to Fig. 16(b), as $V_{\text {ext }}$ trebles from 5 to 15 $\mathrm{kV}$, the collected charge increases by a factor of almost 10 . Thus one simple conclusion from our work is that where possible, one should minimize the laser fluence delivered and maximize $V_{\text {ext }}$ consistent with achieving the ion stage of interest.
The CERN LIS is a benchmark system due to the large range of extraction voltages, laser intensities used and atomic masses studied in conjunction with the use of various electrostatic elements. Thus we compare the DCU-LIS to this system. Reports from a version of the CERN laser ion source $^{9}$ using a $30 \mathrm{~J} \mathrm{CO}_{2}$ laser, with $I=2 \times 10^{12} \mathrm{~W} \mathrm{~cm}^{-2}$ generating Ta ions with $V_{\text {ext }} \sim 60$ to $90 \mathrm{kV}$ (pulsed), indicated peak currents of $30 \mathrm{~mA}$ integrated over all charge states. These currents were detected via a Faraday cup situated 0.3 $\mathrm{m}$ from the extraction gap. Current measurements at the source averaged $\sim 80 \mathrm{~mA}$. An earlier generation laser ion source at CERN (Ref. 14) generating Pb ions for heavy ion injector studies, reported that for $I \sim 2 \times 10^{12} \mathrm{~W} \mathrm{~cm}^{-2}, L$ $=45 \mathrm{~cm}$, and $V_{\mathrm{ext}} \sim 5 \mathrm{kV}$, peak current densities of $\sim 1 \mathrm{~mA}$ had been measured via a Faraday cup placed $3 \mathrm{~m}$ from the cathode, however these results were not charged resolved. The most recent reports from the CERN LIS (Ref. 16) measured peak current for $\mathrm{Pb}^{2+}$ and $\mathrm{Pb}^{4+}$ of $\sim 0.6 \mathrm{~mA}$ and 1.13 $\mathrm{mA}$ at intensities similar to those utilized in our work $\left(I=3.3 \times 10^{10} \mathrm{~W} \mathrm{~cm}^{-2}\right)$, using a field-free region of $1.3 \mathrm{~m}$ and a drift tube of $3 \mathrm{~m}$ in concert with $V_{\text {ext }} \sim 50 \mathrm{kV}$. Charge states from $\mathrm{Pb}^{+}$to $\mathrm{Pb}^{6+}$ were also recorded using an ion energy analyzer. Considering the higher intensities and extraction voltages available together with a substantially longer drift tube at the CERN LIS, our peak current for $\mathrm{Cu}^{2+}$ and $\mathrm{Cu}^{4+}$ ions $\left(V_{\text {ext }}=15 \mathrm{kV} \mathrm{dc}\right)$ of 3.26 and $1.27 \mathrm{~mA}$ (Table III) is an impressive result. Further system enhancement to the DCU-LIS could be achieved by shortening of the drift tube to collect a higher peak current, albeit at the expense of efficient charge separation, and hence accurate quantification of the charge resolved yield might be compromised.

The length of the field-free region plays a key role in placing a ceiling upon the maximum current ${ }^{46}$ which can be extracted $\left(I \propto 1 / L^{3}\right)$. The duration of the plasma signal is directly proportional to $L$, thus it should therefore be minimized to ensure high extracted peak current and high repetition rates. For increasing values of $L$, a larger $V_{\text {ext }}$ is required for efficient ion stage separation in the drift tube. As the literature indicates, the only reason for increasing $L$ is to prevent breakdown by lowering plasma density at the anode. While $L$ (in concert with the laser fluence) defines the plasma density which enters the extraction gap this in turn has a dramatic effect on the kinetic energy of the accelerated ions. Thus on this issue, designers must chose between "high current-low charge state mode" or "low current-high charge state mode," depending on the motivation behind the 
experimental systems individual development. For ion implantation studies, the kinetic energy of the ion is paramount, while for injectors-charge state is usually the key parameter in deciding on a LIS design. In summary, by minimizing the field-free region $L$, we have configured the DCU-LIS to be a "compact, high-pressure, low current high average charge state" laser ion source.

\section{CONCLUSION}

In conclusion we have designed, constructed and characterized a compact "high-pressure" laser ion source. The key performance parameters are a maximum peak current of $I \sim 3.26 \mathrm{~mA}$ for $\mathrm{Cu}^{2+}$ and easily measurable yields of charge states up to $\mathrm{Cu}^{6+}$. The system can employ dc extraction voltage in combination with a wide range of laser fluences. Utilizing a short field-free region results in high extracted current and high average charge state. Due to strong spacecharge forces, continuous and strong beam collimation is required for optimum performance. Future work will focus on higher source potentials via pulsed extraction at higher $V_{\text {ext }}$. Diagnostic of the extracted ion bunch structure will be undertaken implementing new detectors. A radial scanning probe and intensified time resolved imaging will be used to investigate the internal structure of the extracted ion bunches.

\section{ACKNOWLEDGMENTS}

The authors wish to acknowledge Enterprise Ireland for financial support over the course of this project (Grant No: SC/2003/0180).

${ }^{1}$ N. J. Peacock and R. S. Pease, Br. J. Appl. Phys. 2, 1705 (1969).

${ }^{2}$ Y. A. Byckovsky, V. F. Eliseev, Y. P. Kozyrev, and S. M. Silnov, Sov. Patent 324 938, Oct. 1969

${ }^{3}$ O. B. Anan'in, Y. A. Byckovsky, Y. P. Kozyrev, B. Y. Sharkov, and S. M. Silnov, Sov. J. Quantum Electron. 7, 873 (1977).

${ }^{4}$ V. B. Kutner, Y. A. Bykovsky, V. P. Gusev, Y. P. Kozyrev, and V. D. Peklenkov, Rev. Sci. Instrum. 63, 2835 (1992).

${ }^{5}$ J. Sellmair and G. Korshinek, Nucl. Instrum. Methods Phys. Res. A 278, 651 (1989).

${ }^{6}$ V. Mintsev, V. Gryaznov, M. Kulish, V. Fortov, B. Sharkov, A. Golubev, A. Fertman, N. Mescheryakov, W. Süß, D. H. H. Hoffmann, M. Stetter, R. Bock, M. Roth, C. Stöckl, and D. Gardes, Nucl. Instrum. Methods Phys. Res. A 415, (Issue 3), 715 (1998).

${ }^{7}$ V. Dubenkov, B. Sharkov, A. Golubev, A. Shumshurov, O. Shamaev, I. Roudskoy, A. Sireltsov, Y. Satov, K. Makarov, Y. Smakovsky, D. Hoffmann, W. Laux, R. W. Muller, P. Spaedtke, C. Stoekl, B. Wolf, and J. Jakoby, Laser Part. Beams 14, 385 (1996).

${ }^{8}$ M. Okamura, T. Katayama, R. A. Jameson, T. Takeuchi, and H. Kashiwagi, Laser Part. Beams 20, 455 (2002).

${ }^{9}$ P. Fournier, G. Gregoire, H. Kugler, H. Haseroth, N. Lisi, C. Meyer, P. Ostroumov, J.-C. Schnuriger, R. Scrivens, F. Varela Rodriguez, B. H. Wolf, S. Homenko, K. Makarov, Y. Satov, A. Stepanov, S. Kondrashev, B. Sharkov, and A. Shumshurov, Rev. Sci. Instrum. 71, 924 (2000).

${ }^{10}$ P. Fournier, H. Haseroth, H. Kugler, N. Lisi, R. Scrivens, F. Varela Rodriguez, P. Di Lazzaro, F. Flora, S. Duesterer, R. Sauerbrey, H. Schillinger, W. Theobald, L. Veisz, J. W. G. Tisch, and R. A. Smith, Rev. Sci. Instrum. 71, 1405 (2000).

${ }^{11}$ L. Láska, J. Krasa, K. Masek, M. Pfeifer, K. Rohlena, B. Kralikova, J. Skala, E. Woryna, P. Parys, J. Wołowski, W. Mroz, H. Haseroth, A. Golubev, B. Sharkov, and G. Korschinek, Rev. Sci. Instrum. 69, 1072 (1998).

${ }^{12}$ L. Láska, J. Krasa, K. Masek, M. Pfeifer, P. Trenda, B. Kralikova, J. Skala, K. Rohlena, E. Woryna, J. Farny, P. Parys, J. Wolowski, W. Mroz, A. Shumshurov, B. Sharkov, J. Collier, K. Langbein, and H. Haseroth, Rev. Sci. Instrum. 67, 950 (1996).
${ }^{13}$ G. Korschinek and J. Sellmair, Nucl. Instrum. Methods 268, 473 (1988).

${ }^{14}$ Y. Amdidouche, H. Haseroth, A. Kuttenberger, K. Langbein, J. Sellmair, B. Sharkov, O. Shamaev, T. R. Sherwood, and B. Williams, Rev. Sci. Instrum. 63, 2838 (1992).

${ }^{15}$ T. Henkelmann, G. Korschinek, G. Belayev, V. Dubenkov, A. Golubev, S. Latyshev, A. Shumshurov, and B. Wolf, Rev. Sci. Instrum. 63, 2828 (1992).

${ }^{16}$ B. Sharkov and R. Scrivens, IEEE Trans. Plasma Sci. 33, 1778 (2005).

${ }^{17}$ High Voltage Technology, edited by L. L. Alston (Oxford University Press, New York, 1968), p. 65.

${ }^{18}$ L. Cranberg, J. Appl. Phys. 23, 518 (1952).

${ }^{19}$ D. P. Grote, E. Henestroza, and J. W. Kwan, Phys. Rev. ST Accel. Beams 6, $014202(2003)$.

${ }^{20}$ S. Humphries, Jr., C. Bukhart, S. Coffey, G. Cooper, L. K. Len, M. Savage, H. Rutkowski, H. Oona, and R. Shurter, J. Appl. Phys. 59, 1790 (1986).

${ }^{21}$ J. Hasegawa, M. Yoshida, M. Ogawa, Y. Oguri, M. Nakajima, K. Horioka, and J. Kwan, Lawrence Berkeley National Laboratory, Paper-LBNL54724. http://repositories.cdlib.org/lbnl/LBNL-54724 (August 1, 2003).

${ }^{22}$ Y. Oguri, K. Ken-ichi, K. Jun-ichi, J. Hasegawa, M. Yoshida, and M. Ogawa, Phys. Rev. ST Accel. Beams 8, 060401 (2005).

${ }^{23}$ M. Yoshida, J. Hasegawa, J. W. Kwan, Y. Oguri, M. Nakajima, K. Horioka, and M. Ogawa, Jpn. J. Appl. Phys., Part 1 42, 5367 (2003).

${ }^{24}$ J. W. Kwan, F. M. Bieniosek, E. Henestroza, L. Prost, and P. Seidl, Laser Part. Beams 20, 441 (2002).

${ }^{25}$ S. Humphries, Jr., J. Comput. Phys. 204, 587 (2005).

${ }^{26}$ W. C. Wiley and I. H. McLaren, Rev. Sci. Instrum. 26, 1150 (1955).

${ }^{27}$ M. Trinczek, A. Werdich, V. Mironov, P. Guo, A. J. Gonzalez Martınez, J. Braun, J. R. Crespo Lopez-Urrutia, and J. Ullrich, Nucl. Instrum. Methods Phys. Res. B 251, 289 (2006).

${ }^{28}$ J. S. Pearlman, Rev. Sci. Instrum. 48, 1064 (1977).

${ }^{29}$ J. F. Seamans and W. D. Kimure, Rev. Sci. Instrum. 64, 460 (1993)

${ }^{30}$ H. Chuaqui, M. Favre, E. Wyndham, L. Arroyo, and P. Choi, Rev. Sci. Instrum. 60, 141 (1989).

${ }^{31}$ T. Iida, R. Taniguchi, T. Fujimoto, and K. Sumita, Rev. Sci. Instrum. 53, 168 (1982).

${ }^{32}$ J. D. Thomas, G. S. Hodges, D. G. Seely, N. A. Moroz, and T. J. Kvale, Nucl. Instrum. Methods Phys. Res. A 536, 11 (2005).

${ }^{33}$ J. P. Christiansen, D. E. T. F. Ashby, and K. V. Roberts, Comput. Phys. Commun. 7, (Issue 5), 271 (1974).

${ }^{34}$ X. Wang, S. Amoruso, M. Armenante, R. Bruzzese, N. Spinelli, and R. Velotta, Appl. Surf. Sci. 168, 100 (2000).

${ }^{35}$ C. Chu, P. P. Ong, and H. F. Teo, Appl. Surf. Sci. 137, 91 (1999).

${ }^{36}$ K. Saito, T. Okubo, and K. Takamoto, J. Vac. Sci. Technol. A 4, 226 (1986).

${ }^{37}$ O. Sise, M. Ulu, and M. Dogan, Radiat. Phys. Chem. 76, 593 (2007).

${ }^{38}$ J. R. Correa, C. A. Ordonez, and D. L. Weathers, Nucl. Instrum. Methods Phys. Res. B 241, 909 (2005).

${ }^{39}$ T. A. Brown and G. H. Gillespie, Nucl. Instrum. Methods Phys. Res. B 172, 338 (2000).

${ }^{40}$ G. H. Gillespie and T. A. Brown, Nucl. Instrum. Methods Phys. Res. A 427, 315 (1999).

${ }^{41}$ S. S. Harilal, C. V. Bindhu, M. S. Tillack, F. Najmabadi, and A. C. Gaeris, J. Appl. Phys. 93, 2380 (2003).

${ }^{42}$ A. K. Sharma and R. K. Thareja, Appl. Surf. Sci. 243, 68 (2005).

${ }^{43}$ P. E. Dyer, A. Issa, and P. H. Key, Appl. Phys. Lett. 57, 186 (1990).

${ }^{44}$ V. Berardi, S. Amoruso, N. Spinelli, M. Armenante, and R. Velotta, J. Appl. Phys. 76, 8077 (1994).

${ }^{45}$ R. K. Thareja, A. Misra, and S. R. Franklin, Spectrochim. Acta, Part B 53, 1919 (1998)

${ }^{46}$ J. Hasegawa, M. Yoshida, Y. Oguri, M. Ogawa, M. Nakajima, and K. Horioka, Nucl. Instrum. Methods Phys. Res. B 161-163, 1104 (2000).

${ }^{47}$ M. Yoshida, J. Hasegawa, S. Fukata, Y. Oguri, M. Ogawa, M. Nakajima, K. Horioka, S. Maebara, and M. Shiho, Nucl. Instrum. Methods Phys. Res. A 464, 582 (2001).

${ }^{48}$ G. Hall et al., 1995, PS/HP, Note 95-08.

${ }^{49}$ P. Juhasz, M. Vestal, and S. A. Martin, J. Am. Soc. Mass Spectrom. 8, 209 (1997).

${ }^{50}$ B. Sharkov, A. Shumshurov, I. Roudskoy, A. Kilpio, E. Shashkov, N. Kiselev, and P. Pashihin, Laser Part. Beams 17, 741 (1999).

${ }^{51}$ L. Torrisi, S. Gammino, A. M. Mezzasalma, J. Badziak, P. Parys, J. Wolowski, E. Woryna, J. Krasa, L. Laska, M. Pfeifer, K. Rohlena, and F. P. Boody, Appl. Surf. Sci. 217, 319 (2003). 
${ }^{52}$ F. P. Boody, L. Juha, R. Hopfl, B. Kra'likova, J. Krasa, L. Laska, K. Masek, M. Pfeifer, K. Rohlena, K. Skala, P. Straka, H. Hora, J. C. Kelly, D. Giersch, N. Stothard, V. Perina, and E. Woryna, AIP Conf. Proc. 406, 539 (1997).

${ }^{53}$ J. Krása, L. Laska, K. Rohlena, V. Perina, and V. Hnatowicz, Laser Par. Beams 20, 109 (2002).

${ }^{54}$ L. Láska, J. Krasa, K. Masek, M. Pfeifer, K. Rohlena, B. Kralikova, J. Skala, V. Perina, V. Hnatowitz, E. Woryna, P. Parys, J. Wolowski, F. P.
Boody, R. Hopfl, and H. Hora, Czech. J. Phys. 50, (S3), 81 (2000).

${ }^{55}$ E. Woryna, J. Wolowski, B. Kralikova, J. Krasa, L. Laska, M. Pfeifer, K. Rohlena, J. Skala, V. Perina, F. P. Boody, R. Hopfl, and H. Hora, Rev. Sci. Instrum. 71, 949 (2000).

${ }^{56}$ J. Wolowski, J. Badziak, F. P. Boody, H. Hora, V. Hnatowicz, K. Jungwirth, J. Krasa, L. Laska, P. Parys, V. Perina, M. Pfeifer, K. Rohlena, L. Ryc, J. Ullschmied, and E. Woryna, Plasma Phys. Controlled Fusion 44, 1277 (2002). 